\title{
$O$ RETARDAMENTO DA MONTAGEM FINAL DE PRODUTOS COMO ESTRATÉGIA DE MARKETING E DISTRIBUIÇÃO
}

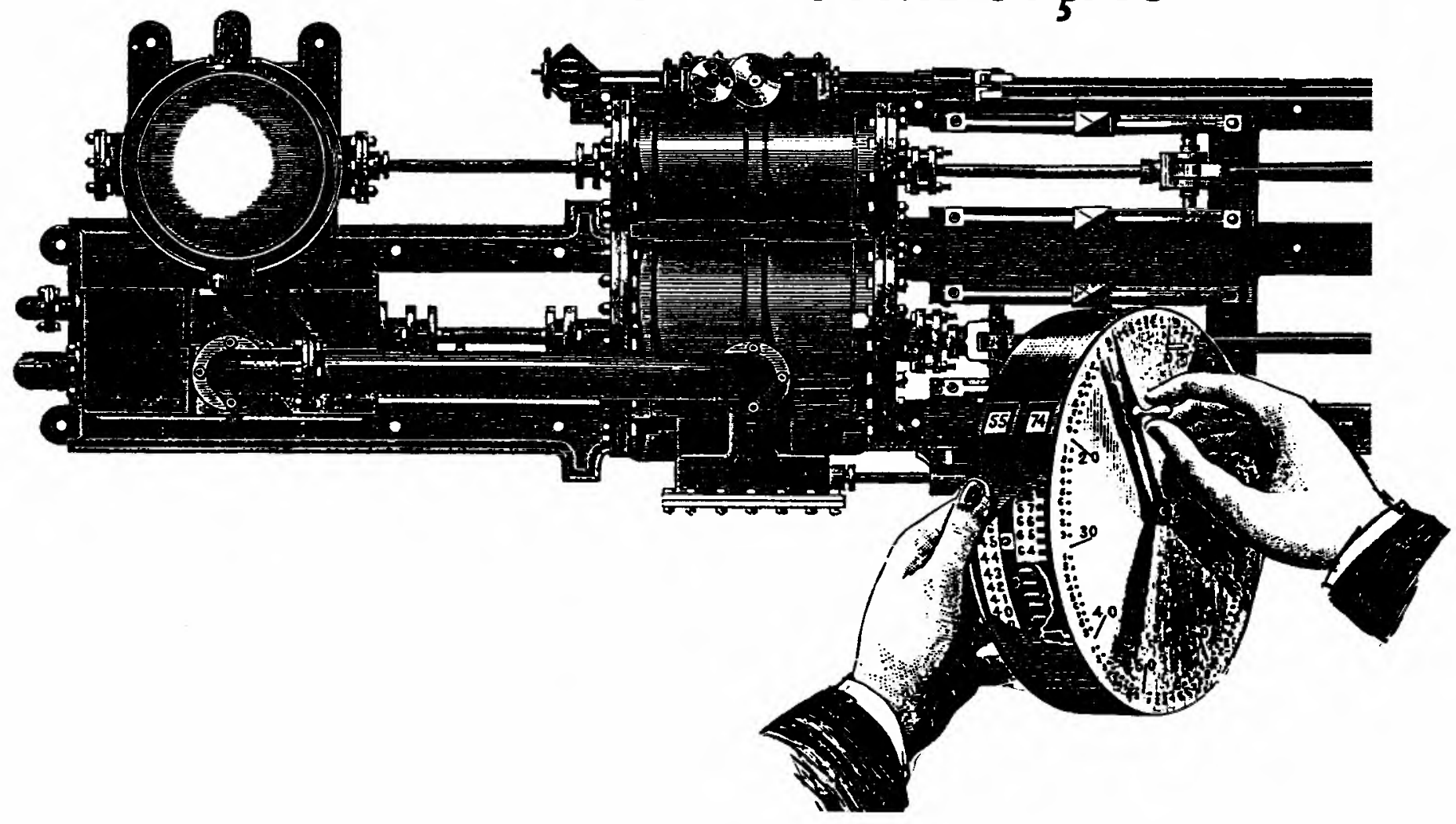

Walter Zinn

Professor do Departamento de Marketing da University of Miami, EUA.

* RESUMO: Geralmente, a montagem final de produtos para envio a armazéns e lojas se decide com base em previsões de venda. Este artigo propõe que economias substanciais nos custos de transporte e de estocagem se viabilizam quando a montagem final de produtos é adiada para depois que o pedido do cliente é recebido. Esse adiamento, conhecido como postponement, é também uma fonte de vantagem competitiva duradoura porque permite que a empresa ofereça a seus clientes uma variedade maior de modelos, tamanhos de embalagem, e cores para seus produtos. Este artigo, primeiramente, distingue quatro tipos de postponement, e, em seguida, sugere diretrizes administrativas para a identificação e implantação de oportunidades para se aplicar o postponement. Um exemplo $\mathrm{nu}$ mérico ilustra a aplicação do postponement.
* PALAVRAS-CHAVE: Estoque, estratégia de marketing, distribuição, logística, varejo.

* ABSTRACT: The decision to assemble products for shipment to warehouses and retail stores is typically based on a sales forecast. This article advocates that substantial savings in transportation and inventory carrying costs can be achieved by delaying product assembly until after a customer order is received. This delay, known as postponement, is also a lasting source of competitive advantage because firms are able to offer customers a broader assortment of models, package sizes, and colors for its products. The article first distinguishes between four types of postponement and then points to research results which suggest managerial guidelines for the identification and implementation of postponement opportunities. A numerical example is provided to illustrate the application of the postponement.

* KEY WORDS: Inventory, marketing strategy, distribution, logistics, retailing. 


\section{INTRODUÇÃO}

0 Grupo Benetton tem apresentado notável sucesso na produção e comércio de vestimentas de lã. Itens em sua extensa linha de produtos são vendidos através de uma rede de 4600 lojas em todo o mundo. Como é que a Benetton deve decidir quais produtos estocar em cada loja? Em que quantidades? Será que todas as lojas devem manter estoques de todos os produtos? A maioria das empresas lida com esse problema usando previsões de venda para estimar a demanda por produto e por loja. A abordagem alternativa da Benetton ilustra o tema deste artigo. A empresa mantém estoques de peças em branco (colarinhos, braços etc.) que só são costuradas e tingidas mediante o recebimento de pedido de uma das lojas especificando o modelo e a cor desejadas'. Esse retardamento para se finalizar a configuração de um produto até que um pedido seja recebido é conhecido como postponement ${ }^{2}$. $O$ postponement é eficaz como estratégia de marketing e distribuição sempre que o nivel de erro na previsão de demanda seja elevado. Dificuldades na previsão de demanda surgem devido à incerteza quanto a condições futuras de mercado e são ampliadas pela extensão da linha de produtos da empresa. Isso porque é claramente mais difícil prever as vendas de um sweater de uma determinada cor e modelo, do que se prever vendas para sweaters em geral. Portanto, quanto maior o número de modelos e cores fabricados, maior o erro na previsão de vendas.

Sempre que as lojas são abastecidas com base em previsões de demanda, erros nas estimativas causam má alocação dos estoques, provocando falta de mercadorias em algumas lojas, e excesso de estoque em outras. "Jeitinhos" típicos utilizados para corrigir esse problema são onerosas transferências de estoque entre lojas ou liquidação de preços naquelas que estão superestocadas. Lojas subestocadas sofrem queda de vendas. Quando se usa o postponement, a montagem de um produto só é finalizada no momento em que se recebe o pedido de um cliente, eliminando-se, portanto, a incerteza nas decisões de produzir e distribuir produtos.

O sistema de distribuição torna-se, assim, menos dependente da previsão de demanda. A conseqüente redução no número de erros na alocação de estoques diminui os custos de transportes. Custos de manutenção de estoques também são reduzidos, já que não há mais necessidade de manter estoques separados para cada cor ou modelo. Por outro lado, como os produtos são montados em peque- nos lotes, conforme chegam os pedidos, os custos de produção podem aumentar, em certos casos.

Além da economia nos custos de transporte e de manutenção de estoques, o postponement proporciona maior flexibilidade à empresa, pois os produtos são estocados desmontados. Isso lhe permite dar ao cliente maior escolha de cores e modelos, com menor investimento em estoques. Conseqüentemente, a Benetton obtém uma vantagem competitiva no mercado, pela oferta de maior variedade de cores e modelos de roupas e por adequá-las a segmentos específicos de mercado. Se quisesse abastecer cada loja com todas as cores e modelos de sua linha de produtos, o volume geral de mercadorias estocadas seria proibitivamente elevado.

Uma vantagem adicional do postponement é a sua durabilidade como estratégia competitiva. As decisões a ele associadas exigem mudanças significativas no processo de fabricação e distribuição de produtos. $O$ tempo e o compromisso organizacional necessários para a implantação de tais mudanças fazem do postponement uma estratégia difícil de ser imitada por concorrentes e, portanto, uma fonte de vantagens competitivas duradouras.

No presente texto, faz-se, inicialmente, uma diferenciação entre quatro tipos de postponement. Eles correspondem ao retardamento de quatro estágios diferentes do processo de produção: etiquetagem, embalagem, montagem e fabricação. A distinção é importante porque os quatro tipos são aplicáveis a diferentes produtos e são afetados por custos diversos, que também serão aqui examinados. A seguir, apresentam-se resultados de pesquisa que sugerem diretrizes administrativas para a identificação de oportunidades de aplicação do postponement como estratégia de marketing e distribuição. Na terceira parte, será fornecido um exemplo prático de aplicação e, finalmente, pretende-se discutir a mensuração e a implantação de decisões relativas ao postponement.

\section{TIPOS DE POSTPONEMENT}

\section{Postponement de Etiquetagem}

O postponement de etiquetagem é potencialmente eficaz como estratégia de marketing e distribuição para empresas que comercializam um produto sob duas ou mais marcas. Os produtos são armazenados sem qualquer rótulo ou etiqueta que identifique sua marca. Estes só são afixados mediante a chegada de um pedido de cliente especificando a marca desejada. Um exemplo de produto em que há 
possibilidade de se usar o postponement de etiquetagem é a massa de tomate em lata. Fabricantes freqüentemente vendem esse produto sob diferentes marcas, como, por exemplo, marcas de clientes varejistas, além da marca própria do fabricante.

O retardamento da etiquetagem até o recebimento do pedido do cliente proporcionará uma redução nos custos de manutenção dos estoques, pois não há necessidade de se manter um para cada marca; basta o armazenamento de latas sem rótulos. Por outro lado, o custo de etiquetagem será mais alto, já que a etiquetagem em pequenos lotes é mais cara do que em grande escala.

\section{Postponement de embalagem}

O postponement de embalagem é viável para produtos vendidos em embalagens de tamanhos diferentes. A economia será ainda maior se o produto for transportado a granel. Certos vinhos da Califórnia são transportados em tonéis e engarrafados nos diferentes centros de distribuição, de acordo com as especificações dos clientes quanto ao tamanho de garrafa desejado. Outro exemplo de postponement de embalagem são as calculadoras eletrônicas. Uma companhia norteamericana exporta calculadoras para a Europa, onde manuais de operação têm que ser impressos em dez línguas diferentes. Em lugar de manter dez estoques separados, as calculadoras são enviadas a um centro de distribuição na Europa e só então são embaladas, com as instruções no idioma correto, conforme vão chegando os pedidos dos clientes.

Com a adoção desse tipo de postponement, os custos de produção podem aumentar, já que a embalagem é feita em pequenos lotes. Os custos de manutenção de estoques são reduzidos, devido à sua consolidação. $\mathrm{O}$ transporte a granel, quando possível (como no exemplo do vinho), pode resultar numa grande economia.

\section{Postponement de montagem}

No caso do postponement de montagem, não só a operação de embalagem, mas a própria montagem do produto é retardada, até que se receba o pedido do cliente. Isso é possível quando um produto básico é vendido em configuraçōes diferentes, mas semelhantes, que refletem as preferências individuais dos clientes. Um bom exemplo é dado pela indústria de computadores pessoais. Um cliente pode ter seu computador montado numa loja varejista, de acordo com suas especificações de componentes, como disk drives, capacidade de memória ou velocida- de de computação. Assim, o postponement de montagem permite aos produtores e varejistas de computadores maximizar o âmbito de escolha do cliente e, ao mesmo tempo, manter baixo o nível de estoques. Isso é possível porque o comerciante mantém estoques dos componentes e não de cada combinação possível de computador. $\mathrm{O}$ postponement de montagem também é adotado pela Caterpillar, uma empresa reconhecida por sua capacidade de usar a distribuição e o serviço ao cliente como armas competitivas. Para se manter competitiva com uma concorrência japonesa crescente, a Caterpillar criou um sistema de produção e distribuição baseado na fabricação de produtos em países de baixo custo de mão-de-obra. Os produtos, ainda desmontados, são transportados a um armazém nos Estados Unidos, onde a montagem final, com todos os componentes opcionais encomendados pelo cliente, só é feita mediante o recebimento de um pedido.

Além do estoque, outros custos também são afetados pelo postponement de montagem. Os custos de produção crescem, porque a montagem em pequenos lotes é mais cara. $\mathrm{O}$ custo de vendas perdidas pode aumentar porque o tempo necessário para a montagem do produto amplia o prazo médio de entrega ao cliente ${ }^{3}$. O custo do transporte é reduzido, porque os produtos são despachados desmontados para o armazém ou loja.

\section{Postponement de fabricação}

Neste tipo de postponement, a fabricação só é concluída após o recebimento de um pedido do cliente. A justificativa econômica fundamental é o transporte e armazenagem de materiais ubíquos. A produção de refrigerantes é um exemplo de postponement de fabricação. Faz-se o transporte do xarope para unidades engarrafadoras, onde a água e o açúcar são adicionados à bebida final. A distribuição de suco de laranja brasileiro para os Estados Unidos segue o mesmo princípio: acrescenta-se água ao concentrado, em fábricas próximas aos pontos de consumo.

O postponement pode aumentar os custos de fabricação, dado o menor lote de produção e de vendas perdidas, graças ao aumento potencial no prazo da entrega. Em compensação, ele reduz os custos de transporte e de manutenção de estoques. Por definição, materiais ubíquos são disponíveis em qualquer lugar, o que faz com que apenas quantidades negligenciáveis precisem ser estocadas. $\mathrm{O}$ quadro 1 resume os quatro tipos de postponement e as categorias de custo associadas a cada um deles.
3. 0 postponement tem ainda um outro efeito no custo da venda perdida, que é 0 de aumentar a disponibilidade de produtos. Esse segundo efeito não foi incluído na elaboração do quadro 1. 
Quadro 1 - Variação no Custo de Distríbuição por Tipo de Postponement

\begin{tabular}{|c|c|c|}
\hline $\begin{array}{c}\text { Tipo dè } \\
\text { Posiponement }\end{array}$ & $\begin{array}{c}\text { Categorias de } \\
\text { Custo }\end{array}$ & $\begin{array}{l}\text { Impacto no } \\
\text { Custo }\end{array}$ \\
\hline \multirow{2}{*}{ Etiquetagem } & Manutenção de estoque & Diminui \\
\hline & Processamento (etiquetagem) & Aumenta \\
\hline \multirow{3}{*}{ Embalagem } & Transporte & Diminui \\
\hline & Manutenção de estoque & Diminui \\
\hline & Processamento (embalagem) & Aumenta \\
\hline \multirow{4}{*}{ Montagem } & Transporte & Diminui \\
\hline & Manutenção de estoque & Diminui \\
\hline & Processamento (montagem) & Aumenta \\
\hline & Vendas perdidas & Aumenta* \\
\hline \multirow{4}{*}{ Fabricação } & Transporte & Diminui \\
\hline & Manutenção de estoque & Diminui \\
\hline & Processamento (fabricação) & Aumenta \\
\hline & Vendas perdidas & Aumenta* \\
\hline
\end{tabular}

* Reflete apenas o aumento no prazo de entrega e não a melhoria na disponibilidade de produtos

\section{OPORTUNIDADES DE POSTPONEMENT}

Quais empresas mais se beneficiariam com o postponement? O quadro 2 apresenta os resultados de uma pesquisa recente, ${ }^{4}$ os quais definem características físicas e de demanda dos produtos como indicadores de oportunidades de postponement. Em testes empíricos, tais indicadores provaram ser úteis na avaliação dessas oportunidades.

Duas regras gerais são aplicáveis a todos os tipos de postponement. A primeira é que as oportunidades de postponement surgem à medida que grandes erros na previsão de demanda aumentam os custos de marketing e distribuição. Portanto, o postponement representa uma oportunidade para empresas que estejam vivendo situações de falta de estoques em determinados armazéns ou lojas e, simultaneamente, excedentes de estoques em outros. Outro sinal de dificuldades na previsão de de- manda é um grande número de transferências entre um armazém e outro, ou entre lojas. A segunda regra é que as oportunidades de postponement são maiores para itens de alto valor unitário, pois o custo de manutenção de estoques é elevado para esses produtos.

Algumas regras adicionais se aplicam a tipos específicos de postponement. $\mathrm{O}$ incentivo para adiar a etiquetagem cresce conforme aumenta o número de marcas sob as quais um produto é vendido. Da mesma forma, há uma oportunidade de postponement de embalagem para produtos vendidos em embalagens de vários tamanhos. Há possibilidade de postponement de montagem, quando a metragem cúbica de um produto é significativamente reduzida se este for transportado desmontado. $\mathrm{E}$, finalmente, a vantagem do postponement de fabricação cresce de acordo com o aumento da presença de materiais ubíquos no peso total do produto. 


\section{UM EXEMPLO ILUSTRATIVO}

Os resultados da pesquisa também demonstram que, geralmente, o custo de manutenção de estoques constitui o efeito mais importante do postponement sobre o custo de marketing e de distribuiçióo. O custo de manutenção de estoques pode ser dividido em dois componentes principais: básico e de segurança. O primeiro componente é o estoque bási- co, necessário para cobrir as vendas de uma empresa durante o período de tempo entre reabastecimentos. Há vários métodos conhecidos para se calcular o estoque básico; o mais freqüentemente citado é o Lote Econômico de Compras.

O estoque de segurança é necessário porque as vendas da empresa flutuam de um período de reabastecimento para outro. Por exemplo, suponhamos uma empresa em que

Quadro 2 - Empresas Potencialmente Interessadas na Utilização do Postponement

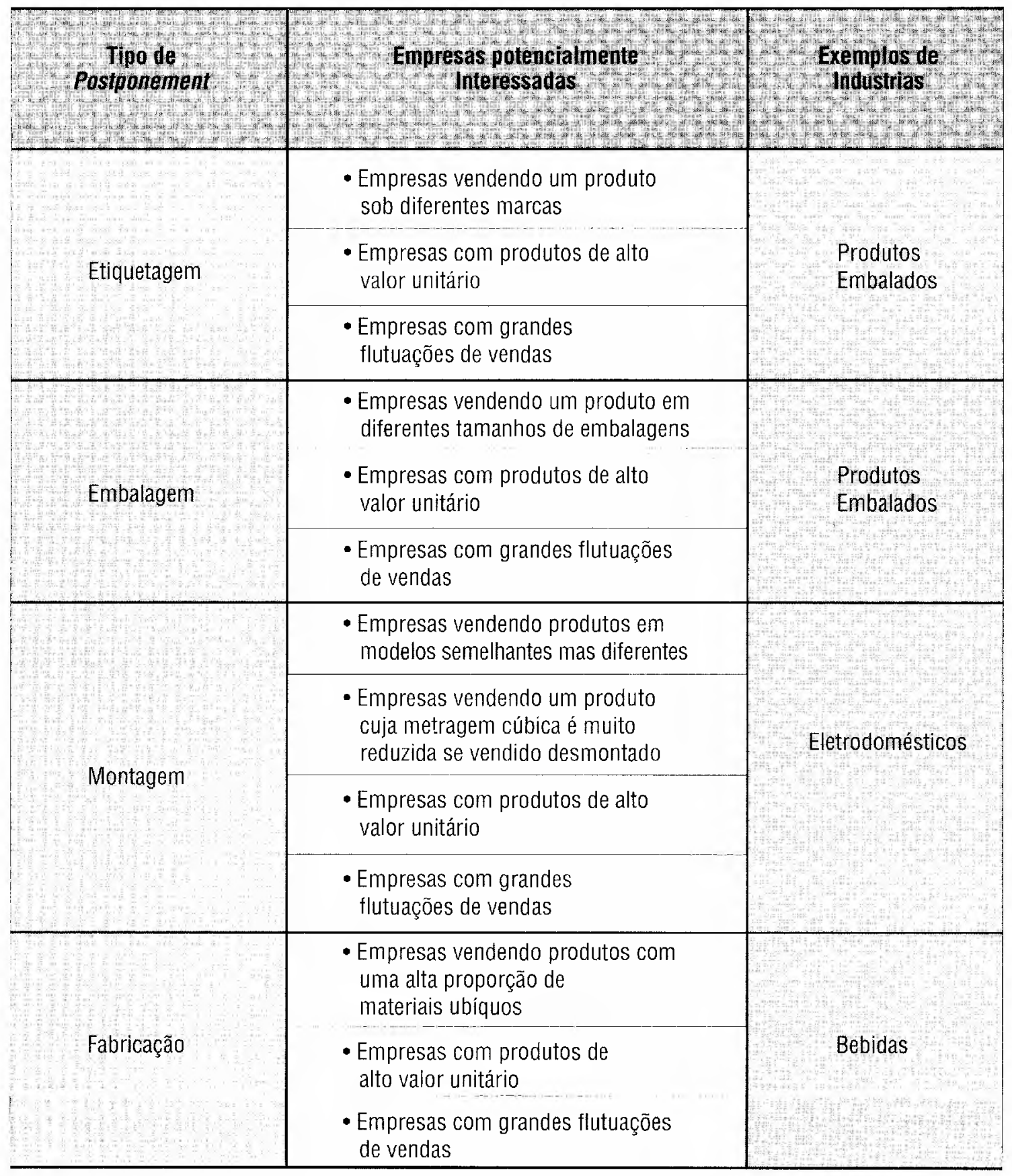


o periodo de reabastecimento seja de uma semana. As vendas semanais raramente são constantes, há semanas de vendas mais altas e semallas de vendas mais baixas. Isso ć inevitável e, até corto ponto, imprevisivel. Portanto, a funçio do estoque de segurança é a de evitar faltas de estoques durante as semanas de venda mais alta.

O cáleulo do estoque de segurança é baseado no desvio-padrào das vendas (em unidades). Quanto maior a variabilidade das ven das, maior o estoque de segurança necessário, porque a incertera da empresa quanto ao volume de vendas numa determinada semana também é maior. Concomitantemente, quanto maior a variabilidade das vendas, maior o desvio-padrão. Portanto, o desvio-padrão das vendas quase sempre reflete adequadamente as necessidades de estoque de segurança de uma empresa.

O efeito do postponement sobre o custo de manutenção de esloques so fay sobre o esto- qué de segurança c não sobre o estoque básico. O quadro 3 demonstra esse efesito usando um caso hipotético.

Imaginemos uma empresa que comercializo uma marca de sabão em pó em três tamanhos de embalagem: pequeno, médio e grande. Suponhamos que a empresa mantenha dois desvios-padroes de vendas como estoque de segrurança, e que o desvio-padrào das vendas seja computado $c 0 m$ base nas vendas das últimas sete semanas. Num sistema tradicional, será necessário manter um estoque de soguranga para cada lamanho de embalagem. a que representa um investimento de 5674 $(1758+2762+1154)$ unidades, conforme indicado no quactro 3.

So o pustpunement de embalagem a adotado, estoca-se o sabáo em pó a grancl. O produto só ć embalado yuando a empresa recebe um pedido de cliente especificando o tamanho de embalagem desejado. Nesse caso, o estoque de segurança necestário é calculado

Quadro 3 - Exemplo do Efeito do Pastponement no Estoque de Segurança (ES)

\begin{tabular}{|c|c|c|c|c|}
\hline \multicolumn{5}{|c|}{ Produto: Sabão em pó, vendido em 3 embalagens: pequeno, médio e grande } \\
\hline \multirow{2}{*}{ Semana } & \multicolumn{4}{|c|}{ Vendas } \\
\hline & $\mathbf{P}$ & M & G & Total \\
\hline 1 & 2773 & 2506 & 1475 & 6754 \\
\hline 2 & 846 & 1024 & 1805 & 6675 \\
\hline 3 & 2558 & 929 & 1848 & 5335 \\
\hline 4 & 1428 & 3832 & 842 & 6102 \\
\hline 5 & 1971 & 1071 & 1494 & 4536 \\
\hline 6 & 421 & 3592 & 480 & 4493 \\
\hline 7 & 2198 & 4109 & 564 & 6871 \\
\hline Média & 1742 & 2866 & 1215 & 5824 \\
\hline D. Padrão & 879 & 1381 & 577 & 1035 \\
\hline ES & 1758 & 2762 & 1154 & 2070 \\
\hline EM & 3500 & 5628 & 2369 & 7895 \\
\hline $\begin{array}{l}\text { no Estoque } \\
\text { no Estoque }\end{array}$ & $\begin{array}{l}(\mathrm{ES}) \\
(\mathrm{EM})\end{array}$ & & & \\
\hline
\end{tabular}


com base no desvio-padrão das vendas totais. O quadro 3 indica que esse número é 2070 unidades, ou seja, uma redução de $63 \%$ no estoque de segurança. A redução no estoque médio é de $31 \%$.

O efeito do postponement sobre os demais custos de distribuição decorre desta ilustração. A disponibilidade de estoque é maior porque não acontece de o tamanho de embalagem desejado pelo cliente estar em falta. Isso reduz o custo de transporte porque ressuprimentos de emergência são menos necessários. Por outro lado, em alguns casos, o custo de embalar produtos pode aumentar, em decorrência da menor escala de operações.

\section{MEDIÇÃO E IMPLANTAÇÃO DAS OPORTUNIDADES DE POSTPONEMENT}

Observe-se, no quadro 1 , que o postponement aumenta alguns custos de distribuição e diminui outros. Portanto, é necessário medir os custos para avaliar o efeito conjunto de uma oportunidade de postponement para um produto. O levantamento de custos necessário para decisões de postponement não é pequeno. Gerentes precisam avaliar os custos de postponement versus os custos relativos ao status quo, ou seja, a prática corrente de se alocar produtos para armazéns ou lojas, com base em previsões de vendas. Mais especificamente, os custos de manutenção de estoques, transporte, perda de vendas devida ao aumento do prazo de entrega e processamento (etiquetagem, embalagem, montagem ou fabricação) devem ser coletados, para que o custo de distribuição por unidade de produto possa ser estimado.

Um problema comum envolvendo decisões de postponement é a não disponibilidade de custos de distribuição por produto em sistemas contábeis mais tradicionais. Existem, entretanto, sistemas de contabilidade capazes de providenciar dados necessários para a análise de postponement. Esses sistemas se baseiam em custeios diretos. Custos diretos ignoram os custos que não podem ser diretamente atribuídos a um produto específico. $\mathrm{O}$ critério usado para atribuir custos a um produto inclui apenas aqueles que seriam eliminados, se o produto saísse de linha. A maior vantagem do custo direto é evitar distorções introduzidas por regras de alocação de custos indiretos, que freqüentemente são arbitrárias. Um sistema muito empregado de custeio direto é a LDP ( $D P P$ em inglês), Lucratividade Direta do Produto, que é muito usada na indústria de bens embalados. Uma pesquisa de 1986 revela que $80 \%$ das empresas varejistas dos Estados Unidos, ou já têm, ou irão intro- duzir a LDP num futuro próximo ${ }^{5}$. Na implantação das oportunidades de postponement, algumas questões adicionais precisam ser consideradas. $O$ controle de qualidade tem que ser descentralizado, no caso da descentralização do processamento para o nível de loja ou armazém. A implantação do postponement no varejo apresenta três diferenças principais, quando comparada com a implantação no nível de armazém. Primeiro, as instalações varejistas tipicamente não são de propriedade do fabricante ou firma distribuidora, o que acrescenta uma dimensão interorganizacional à implantação do postponement. Alguns varejistas podem ser a favor do postponement, enquanto outros são contra. A segunda diferença provém da ameaça de adulteração dos produtos, o que tem sido um grande problema nos últimos anos, e pode impedir que as empresas processem seus produtos no nível de varejo, mesmo havendo vantagens de custo.

\section{CONCLUSÃO}

O crescimento do postponement como estratégia de distribuição é uma realidade no mundo de negócios de hoje. O número de produtos disponíveis para escolha do consumidor cresceu exponencialmente. A maioria dos itens são oferecidos em múltiplas variações, de acordo com as necessidades de segmentos específicos de mercado. Esse crescimento ex ponencial tem trazido um novo patamar de complexidade para a distribuição de produtos, pois se torna cada vez mais difícil fazer uma previsão de demanda para cada variação de produto em cada ponto de venda. Tal dificuldade resulta, tipicamente, em erros cada vez mais freqüentes em previsão de vendas e, conseqüentemente, em despachos de produtos errados e desequilíbrios de estoques. $\mathrm{O}$ postponement representa uma importante alternativa estratégica a sistemas de distribuição baseados em previsão de vendas. Ao retardar a configuração final de um produto até que a natureza específica da demanda do consumidor seja conhecida, as empresas realmente evitam o risco de enviar produtos para localidades erradas e de manter estoques que não se adeqüem às necessidades dos consumidores. As empresas também podem evitar custos desnecessários de transporte, negociando melhores taxas de frete no despacho de mercadorias a granel ou de produtos desmontados. Finalmente, o postponement dá às empresas uma oportunidade de se diferenciarem da concorrência, oferecendo a seus clientes uma gama mais ampla de produtos, enquanto mantêm um investimento baixo em estoques.
5. GORDON, Harris; O' CONNOR Daniel \& PHIPPS, John. “Direct Product Profit: Introducing a Comprehensive Measure of Retail Performance". Retail Control, setembro de 1986, pp.36-43. 